\title{
Micropapillary carcinoma of the breast: A case review at Mankweng Hospital breast oncology clinic in Limpopo Province, South Africa
}

\author{
J G Mthembu, MB ChB; M M Z U Bhuiyan, MBBS, DTH, FRCS (Glasgow), MMed (Surg) \\ Department of General Surgery, Mankweng Hospital, University of Limpopo, Polokwane, South Africa
}

Corresponding author: M M U Bhuiyan (bhuiyanmirza@gmail.com)

Invasive micropapillary carcinoma (IMPC) of the breast is a clinically aggressive rare form of breast cancer. Patients with IMPC present with higher clinical stages, higher histological degrees, higher rate of lymph-vascular invasion and axillary lymph node extracapsular extension. In this case report, we seek to explore and share our experience of invasive micropapillary carcinoma of the breast and give a literature review of the standard of care.

S Afr Med J 2021;111(11b):1138-1139. https://doi.org/10.7196/SAMJ.2021.v111i11b.16105

Breast cancer is the most common cancer in females. ${ }^{[1]}$ Invasive micropapillary carcinoma (IMPC) of the breast is a clinically aggressive and rare form of invasive ductal carcinoma (IDC), accounting for $<6 \%$ of breast cancer cases. ${ }^{[2,3]}$ There are no specific distinguishing features to differentiate between IMPC and IDC, and $80 \%$ of patients have lymph node metastasis at presentation with histological findings highly positive for oestrogen receptor (ER) and human epidermal growth receptor-2 (c-erbB-2) (88\% and $84 \%$, respectively). ${ }^{[4-6]}$ IMPC was first described in 1980, and it was thought that patients with IMPC experience worse outcomes than those with IDC because of its higher propensity for lymph-vascular invasion and lymph node metastasis. ${ }^{[4-8]}$ The main objective of this case report is to share our experience with IMPC and give a literature review of the standard of care. Ethical approval was obtained from the Pietersburg/ Mankweng Hospital Research Ethics Committee (ref no. PMREC 25 AUGUST UL 2021/E).

\section{Case presentation}

An 81-year-old African female patient presented at Mankweng Hospital breast oncology clinic (Limpopo Province, South Africa) as a referral from a peripheral hospital. The main complaint was progressive swelling of the left upper limb involving the ipsilateral breast. According to the patient, she had a prick on the left hand for more than 18 months, then her upper limb was progressively swelling and ultimately led to left breast involvement. She consulted various traditional healers at the time when she started experiencing symptoms; however, there was no improvement to her condition. It is at this point that she started seeking medical attention at her local hospital more than a year after the onset of her symptoms. A biopsy on the breast mass was done on the initial presentation prior to breast oncology referral.

She was a healthy individual, multiparous with a total of 5 children. The onset of menarche and menopause is not known, and she had no significant family history of breast cancer.

Upon examination, the left upper limb was swollen from the fingers all the way through to the shoulder joint and also involving the left breast. There were multiple ulcerated lesions and masses of various sizes on the breast, axilla and shoulder region (Fig. 1). There was notable peau d'orange skin changes and nipple retraction. There were no obvious abnormalities detected on the contralateral upper limb, and cardiovascular, respiratory, abdomen and musculoskeletal systems.

Histopathological evaluation of the incision biopsy of the left breast mass showed skin-surfaced tissue, invasive neoplasm, and small nests of malignant cells, largely involving the lymphatic vessels. There were markedly pleomorphic cells that displayed brisk mitotic activity and showed no tubule-forming behaviour. No evidence of ductal carcinoma in situ was displayed in the tissue section. These features are in keeping with IMPC.

The patient was referred to the medical oncology clinic; however, she ultimately succumbed to her illness before the date of her treatment.

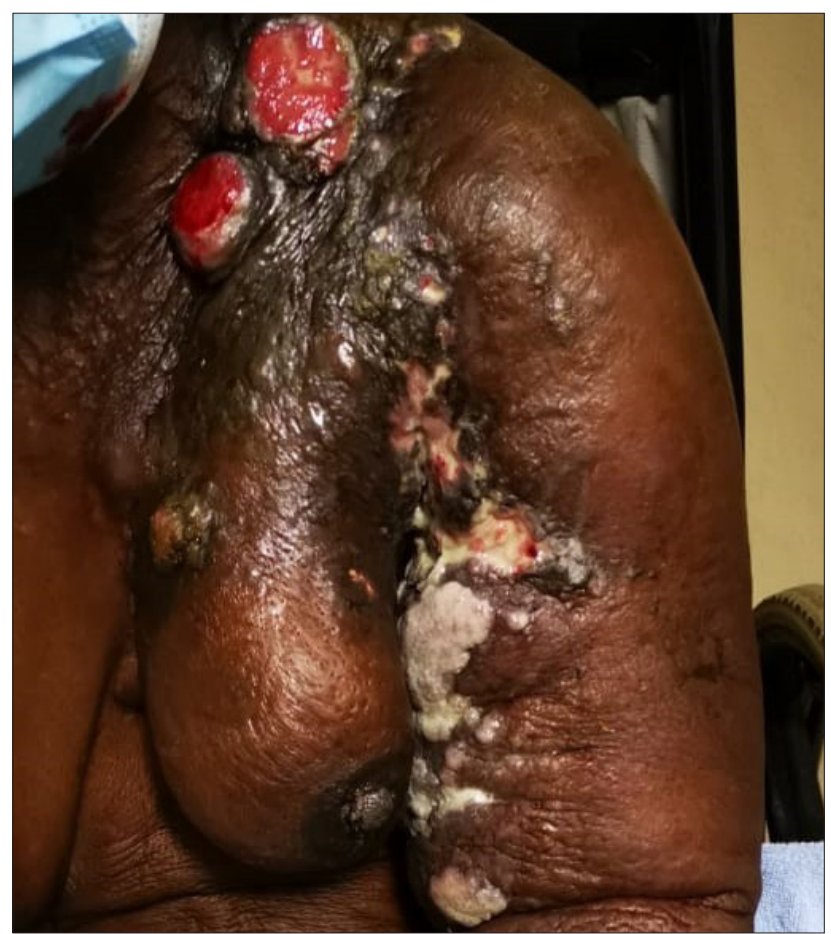

Fig. 1. Advanced left-sided breast cancer with ulcerated lesions, masses of various sizes and also extending to the left upper limb. 


\section{Discussion}

The most common presentation of IMPC is a breast lump (61\%) that may be associated with nipple retraction and/or erythema. The left breast has been shown to be commonly involved ( $71 \%$ of the IMPC cases), followed by the right breast (25\%) and both breasts in $3 \%$ of the cases. ${ }^{[2]}$

Imaging studies show features of a typical breast malignancy, with MRI further showing features of lymphatic infiltration. ${ }^{[2,5]}$ This implies that MRI can be used for diagnosis and treatment planning. ${ }^{[5]}$

Patients with IMPC present with higher clinical stages, higher histological degrees, higher rate of lymph-vascular invasion and axillary lymph node extracapsular extension. ${ }^{[7,8]}$ IMPC patients have been shown to have a more unfavourable prognosis for loco-regional recurrence than IDC patients. However, there is no statistically significant difference between patients with IMPC and IDC as indicated by relapse-free survival (odds ratio (OR) 2.04; 95\% confidence interval (CI) 1.63 - 2.55) and local regional recurrencefree survival (OR 2.82; 95\% CI $1.90-4.17),{ }^{[6,79-12]}$ suggesting that radical or proactive clinical therapy is unnecessary. Treatment is individualised to include tailored therapeutic interventions or multidisciplinary approaches.

\section{Conclusion}

Invasive micropapillary carcinoma is a rare aggressive variant of breast cancer. Its frequent lymph-vascular invasion and high tumour grades correlate with its aggressive nature; however, no significant difference in overall survival has been proven yet. Patients must be encouraged to seek medical attention early as this can aid in better prognosis, and reduced morbidity and mortality.

\section{Declaration. None.}

Acknowledgements. None.

Author contributions. Equal contributions.

Funding. None.

Conflicts of interest. None.

\footnotetext{
1. Smittenaar CR, Petersen KA, Stewart K, Moitt N. Cancer incidence and mortality projections in the UK until 2035. Br J Cancer 2016;115(9):1147-1155. https://doi.org/10.1038/bjc.2016.304

2. Beatriz Adrada EA, Gilcrease M, Yang WT. Invasive microcapillary carcinoma of the breast: Mammographic, sonographic, and MRI features. Women's Imaging 2009:6. https://doi.org/10.2214/ ajr.08.1537

3. Coyle EA, Taj H, Comba I, Vasquez J, Zayat V. Invasive micropapillary carcinoma: A rare case of male 3. Coyle EA, Taj H, Comba I, Vasquez J, Zayat V. Invasive micropapillary carcinoma:
breast cancer. Cureus 2020;12(9):e10571. https://doi.org/10.7759\%2Fcureus.10571

4. Cui ZQ, Feng JH, Zhao YJ. Clinicopathological features of invasive micropapillary carcinoma of the 4. Cui ZQ, Feng JH, Zhao YJ. Clinicopathological features of invasive micropapillary
breast. Oncol Lett 2015;9(3):1163-1166. https://doi.org/10.3892\%2Fol.2014.2806

breast. Oncol Lett 2015;9(3):1163-1166. https://doi.org/ $10.3892 \% 2$ Fol.2014.2806
5. Han CH, Yao WG, He J, Gao ZB, Hu HJ. MRI and the pathology of breast invasive micropapillary carcinoma. Oncol Lett 2020;20(3):2811-2819. https://doi.org/10.3892\%2Fol.2020.11848

6. Wu Y, Zhang N, Yang Q. The prognosis of invasive micropapillary carcinoma compared with invasive ductal carcinoma in the breast: A meta-analysis. BMC Cancer 2017;17(1):839. https://doi.org/10.1186/ s12885-017-3855-7

7. Ye F, Yu P, Li N, et al. Prognosis of invasive micropapillary carcinoma compared with invasive ductal carcinoma in breast: A meta-analysis of PSM studies. Breast 2020;51:11-20. https://doi.org/10.1016/j. breast.2020.01.041

8. Hashmi AA, Aijaz S, Mahboob R, et al. Clinicopathologic features of invasive metaplastic and micropapillary breast carcinoma: Comparison with invasive ductal carcinoma of breast. BMC Res Notes 2018;11(1):531. https://doi.org/10.1186/s13104-018-3623-z

9. Hao S, Zhao YY, Peng JJ, et al. Invasive micropapillary carcinoma of the breast had no difference in prognosis compared with invasive ductal carcinoma: A propensity-matched analysis. Sci Rep
in in prognosis compared with invasive ductal carcinoma: $A$ p

10. Tang SL, Yang JQ, Du ZG, et al. Clinicopathologic study of invasive micropapillary carcinoma of the breast. Oncotarget 2017;8(26):42455-42465. https://doi.org/10.18632\%2Foncotarget.16405

11. Tsushimi T, Mori H, Harada T, Ikeda $\mathrm{Y}$, Ohnishi H. Invasive micropapillary carcinoma of the breast in a male patient: Report of a case. Int J Surg Case Rep 2013;4(11):988-991. https://doi.org/10.1016/j. ijscr.2013.09.00

12. Mahe E, Farag M, Boutross-Tadross O. Invasive micropapillary breast carcinoma: a retrospective study of classification by pathological parameters. Malaysia J Pathol 2013;35(2):133-138.
}

Accepted 5 September 2021. 